\title{
Connection between the COVID-19 pandemic, war trauma reminders, perceived stress, loneliness, and PTSD in Bosnia and Herzegovina
}

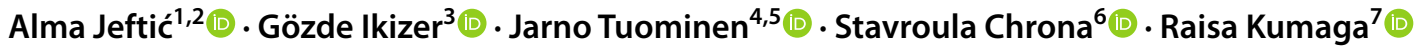 \\ Accepted: 13 October 2021 \\ (c) The Author(s), under exclusive licence to Springer Science+Business Media, LLC, part of Springer Nature 2021
}

\begin{abstract}
In order to gain a better understanding of what happens during the COVID-19 pandemic to those who were previously traumatized, this study investigated perceived stress and severity of PTSD symptoms during the COVID-19 pandemic in people who experienced the 1992-1995 war in Bosnia and Herzegovina. It was also examined how reminders of past trauma and loneliness instigated by the COVID-19 crisis relate to current stress and PTSD symptoms. The sample consisted of 123 participants (74.8\% women). Participants responded to assessments of sociodemographic characteristics, exposure to COVIDrelated information, concerns over disease, severity of exposure to war, frequency and intensity of war trauma reminders, loneliness, stress, and severity of PTSD symptoms. Data was collected as part of the COVIDiSTRESS Global Survey. Results showed that in a population previously exposed to the effects of war, severity of PTSD symptoms was positively related to perceived stress, and loneliness during the pandemic significantly mediated this relationship. Intensity of exposure to war trauma reminders was associated with higher levels of PTSD symptom severity. Higher severity of PTSD symptoms was related to forced displacement during the war. Moreover, higher stress was related to increased concerns over disease. To conclude, those exposed to war may be more affected by the global COVID-19 pandemic and preventive measures that accompany it, while loneliness mediates the effects of PTSD and perceived stress in this population.
\end{abstract}

Keywords Posttraumatic stress disorder $\cdot$ Stress $\cdot$ Loneliness $\cdot$ War trauma $\cdot$ Trauma reminders $\cdot$ COVID-19

Alma Jeftić and Gözde Ikizer share first authorship.

Alma Jeftić

alma.jeftic@gmail.com

1 Peace Research Institute, International Christian University, 3 Chome-10-2 Osawa, Tokyo, Mitaka 181-8585, Japan

2 Department of Psychology, University of Belgrade, Beograd, Serbia

3 Department of Psychology, TOBB University of Economics and Technology, Ankara, Turkey

4 Department of Psychology and Speech-Language Pathology, University of Turku, Turku, Finland

5 Faculty of Social Sciences, University of Helsinki, Helsinki, Finland

6 School of History, Anthropology, Philosophy and Politics, Queen's University Belfast, Belfast, UK

7 Department of Psychology, University of East London, London, UK

\section{Introduction}

The coronavirus disease 2019 (COVID-19) pandemic has resulted in profound psychological distress across the globe (Serafini et al., 2020) with alarming implications for health and functioning of both individuals and communities (Pfefferbaum \& North, 2020). This current public health crisis and its mitigation efforts adversely affected social support structures and limited personal relationships, while simultaneously increasing the number and intensity of several stressors (Park et al., 2020). While preventive measures are necessary to curtail the spread of the pandemic, they also carry negative psychological impact in themselves. In fact, several of the imposed measures aimed at reducing the spread of the virus such as quarantine have been found to have adverse psychological impact including posttraumatic stress (Brooks et al., 2020; Holmes et al., 2020).

In situations of crisis such as the COVID-19 pandemic, measures imposed by governments such as isolation, quarantine, restrictions on places in combination with their consequences such as social and economic instability and 
tensions have the potential to act as powerful stimuli of trauma reminders. Those reminders symbolize or resemble aspects of previous traumatic experiences, and reactivate posttraumatic stress reactions (Brewin et al., 1996; Layne et al., 2006). In other words, trauma reminders are important triggers for bringing up memories related to the earlier traumatic events and play a key role in predicting posttraumatic stress symptoms (Howell et al., 2015; Streb et al., 2017). Van der Kolk and Fisler (1995) have previously suggested that traumatic memories are consistent with intense emotions, flashbacks, somatic sensations, and interpersonal reenactment which occurs when trauma survivors are exposed to reminders. This means that even after many years of the trauma, survivors may relive their experience as vivid as when the trauma first occurred. Furthermore, reminders may trigger re-experiencing of the past trauma, activating trauma-related fear and hyperarousal (Tsur et al., 2018). Especially individuals with posttraumatic stress disorder (PTSD) might experience heightened physiological arousal due to traumatic reminders without any direct recollection of the event (Ehlers \& Clark, 2000; van der Kolk, 2000; Zoellner et al., 2020). Following war experiences, being upset by trauma reminders and physical reactivity to reminders have been previously shown to be among the most common PTSD symptoms (Ai et al., 2002). Although such reminders lose their strength and intensity over time (Howell et al., 2015), it has been reported that exposure to trauma reminders may be more strongly related with PTSD in the long term (Glad et al., 2017). Given that public health crises like COVID19 and preventive measures (e.g., curfew, lockdown, travel restrictions) may act as potent reminders, it is important to examine whether such reminders are associated with psychological functioning during the pandemic.

The current pandemic has been associated with an increased prevalence of mental health problems in the general population including PTSD (e.g., Castelli et al., 2020; Chen et al., 2020; Daly and Robinson, 2021; Di Crosta et al., 2020; Ikizer et al., 2021; Karatzias et al., 2020; Liu et al., 2020; Luo et al., 2020; Tang et al., 2020; Wang et al., 2020). However, it is unclear what happens to those that already are stressed and/or have PTSD symptoms, such as the ones who have experienced war trauma in Bosnia and Herzegovina (for a discussion on war trauma and the pandemic see Okorn et al., 2020). Also, it is still underexplored how isolation and lack of social support or reminders of past trauma can relate to current stress levels and severity of PTSD symptoms. Hence, the current study aimed to examine how people who survived the 1992-1995 war in Bosnia and Herzegovina reacted to the COVID-19 pandemic and related measures.

The war in Bosnia and Herzegovina started in 1992 and ended after the ratification of the Dayton Peace Agreement in 1995, which kept Bosnia as a single state made up of two parts, the Federation of Bosnia-Herzegovina, and the
Republic of Srpska. The war was characterized by mass atrocities, loss of lives, concentration camps, and large-scale destruction. People who survived the war (including those who suffered its indirect consequences), ended up with the signs of war trauma; however, there was no adequate psychological and psychiatric assistance in the immediate postwar period (Jeftić, 2019).

The vast majority of people who lived through the 19921995 war in Bosnia and Herzegovina were exposed to traumatic events such as physical injuries, loss of loved ones, and forced displacement. Many people lost their properties and experienced significant interruptions to their everyday life. Studies about the psychological consequences of previous traumatic experiences including the war in Bosnia and Herzegovina (e.g., Comtesse et al., 2019; Durakovic-Belko et al., 2003; Papageorgiou et al., 2000; Powell et al., 2010; Smith et al., 2001) have shown that the risk for psychological maladjustment was high in the case of exposure to war trauma. Those studies have shown that PTSD was commonly observed in survivors during the postwar period along with traumatic grief, depression, and anxiety.

Citizens in Bosnia and Herzegovina had to cope with heavy stressors during the war but also had to cope with war-related stressors in the aftermath of the war. Postwar stressors have been shown to be associated with an increase in the intensity and number of PTSD symptoms in Bosnian samples (Klarić et al., 2007). People displaced in the Bosnian war reported feeling insufficient and losing a sense of personal worth, as well as feeling listless and fatigued (Carballo et al., 2004). The effects of war seem to persist over time; the impact of such war trauma has been previously suggested to be significant and long-lasting for survivors (Shemyakina \& Plagnol, 2013). In a representative sample from Bosnia and Herzegovina, Ringdal et al. (2008) found that even eight years after the war, about $13 \%$ percent of respondents had war-related distress symptoms above the threshold. A recent longitudinal study in three samples of Bosnian war survivors showed that general psychological distress was evident almost 15 years after the war, with current stressful living conditions including health problems, debts, separation from loved ones etc. acting as important predictors (Comtesse et al., 2019).

Almost 25 years after the 1992-1995 war, as a consequence of the COVID-19 pandemic citizens in Bosnia and Herzegovina had to face school closures and regulation of schools, national curfew, provincial lockdowns, external and internal border restrictions, limitations to personal movement, the imposition of self-quarantine rules, restrictions of mass gatherings, and rules of social distancing as well as cope with restrictions and regulation of businesses and government services resulting into substantive economic concerns such as risk of unemployment (Cheng et al., 2020). The first registered case of COVID-19 in Bosnia and 
Herzegovina appeared on March 5, 2020 (Radio Slobodna Evropa, 2020). The Council of Ministers in Bosnia and Herzegovina declared a state of emergency ${ }^{1}$ on March 17, 2020. From March 21st, the restrictive measure of curfew was introduced along with other preventive measures such as use of masks and disinfectants in public spaces to name a few (Cheng et al., 2020; Radiosarajevo.ba, 2020). There were media reports contradictory to one another and to official statements, possibly exposing the population to feelings of intense fear and helplessness (Turjačanin et al., 2020). The curfew was abolished first in the Federation Bosnia and Herzegovina (24 April), and then in the Republic of Srpska (22 May) (Dnevni Avaz, 2020). In place of more stringent measures such as lockdown, the state decided to impose milder preventive measures such as mask wearing, social distancing, and handwashing.

In the context of COVID-19, media coverage on the virus has intensified since the early days, reaching its peak during the period of lockdown that various countries have experienced across the globe. Media coverage around the globe again switched to topics (e.g., life in quarantine) similar to what had been experienced during the 1992-1995 war in Bosnia and Herzegovina, and threat to life reemerged, making trauma memories resurface. As such, exposure to trauma reminders for this subset of the population has become more frequent and intense. Indeed, previous studies (e.g., Glad et al., 2017; Hilton, 1997; Silver et al., 2013) have shown a positive association between the severity of posttraumatic stress symptoms and frequency and intensity of trauma reminders in the context of war and terrorism. Hence, since memory of traumatic events has been suggested to be at the core of PTSD symptomatology (Kevers et al., 2016), citizens in Bosnia and Herzegovina who experienced the 1992-1995 war may be acutely reminded of their trauma due to exposure to stress-provoking news in the media and events in their surroundings all of which can cause higher stress levels. Regarding the psychological impact of COVID19 in Bosnia and Herzegovina, previous studies in Bosnian samples have shown that although citizens' stress levels during the COVID-19 pandemic were low-to-moderate, overthinking, change in sleep patterns, and nervousness were frequently reported (Jankovic \& Cehajic-Clancy, 2020); and almost one third of the population had depressive symptoms (Šljivo et al., 2020). Moreover, in studies with multicountry samples including community samples from Bosnia and Herzegovina, it has been shown that the pandemic was associated with deterioration of quality of life (Repišti et al., 2020) and worsening of pre-existing psychiatric conditions (Gobbi et al., 2020).

\footnotetext{
1 The original expression in Bosnian is "stanje prirodne i druge nesreće" ("state of natural and other disaster").
}

During challenging times, the presence of others and their support can be important for coping with stress. However, mandatory or self-imposed quarantine in the context of the COVID-19 pandemic can aptly remove some of the organic social support networks and daily relationships —one of the key resilience-enhancing means to cope with traumatic experiences (Southwick et al., 2016) — and this can be an acute stressor for many people, increasing feelings of loneliness. Loneliness is "a situation experienced by the individual as one where there is an unpleasant or inadmissible lack of (quality of) certain relationships" (de Jong-Gierveld, 1998, p. 73). Higher levels of loneliness have been previously shown to be associated with higher severity of PTSD symptoms (e.g., Solomon et al., 2015) and perceived stress (e.g., Kuwert et al., 2014) in samples exposed to war. Van der Velden et al. (2018) also showed that especially adults with high levels of PTSD were more at risk for loneliness following potentially traumatic events compared to others with adults who were non-affected or had low levels of PTSD. Moreover, loneliness has a synergistic effect with social isolation on mortality, suggesting that people concurrently lonely and isolated have a high risk of mortality (Beller \& Wagner, 2018). In a study with Bosnian refugees, Miller et al. (2002) suggested that just as isolation may worsen trauma symptoms, people experiencing PTSD symptoms might self-isolate as a respite from distressing reminders. In addition, following the war in Bosnia and Herzegovina, intrusive recollections were shown to be positively related with feelings of distrust (Mooren \& Kleber, 2001). Therefore, pre-existing trauma symptoms can foster avoidance from social interactions. To conclude, loneliness can be both an adverse outcome of traumatic events and a risk factor for negative psychological and physical outcomes, mediating the link between pre-existing PTSD symptomatology and heightened stress levels during the pandemic. Especially those with pre-existing traumatic experiences and symptoms can be adversely affected by the current COVID-19 pandemic and the mitigation actions. During the pandemic, feelings of lack of companionship have been reported in countries (including Bosnia and Herzegovina) even with relatively lower death rates and milder restrictions (Lo Coco et al., 2021). Hence, it would be important to understand how loneliness contributes to negative mental health outcomes including increased levels of perceived stress in samples previously exposed to trauma.

Based on the literature review presented above, this study aimed to, first, understand how those who already experienced stress and/or had PTSD symptoms fared during the COVID-19 pandemic, and second, how loneliness during the pandemic and reminders of past trauma related to PTSD symptoms and perceived stress. Our pre-registered hypotheses (Jeftić et al., 2020) were as follows (see Fig. 1 for a graphical representation of the study hypotheses): 


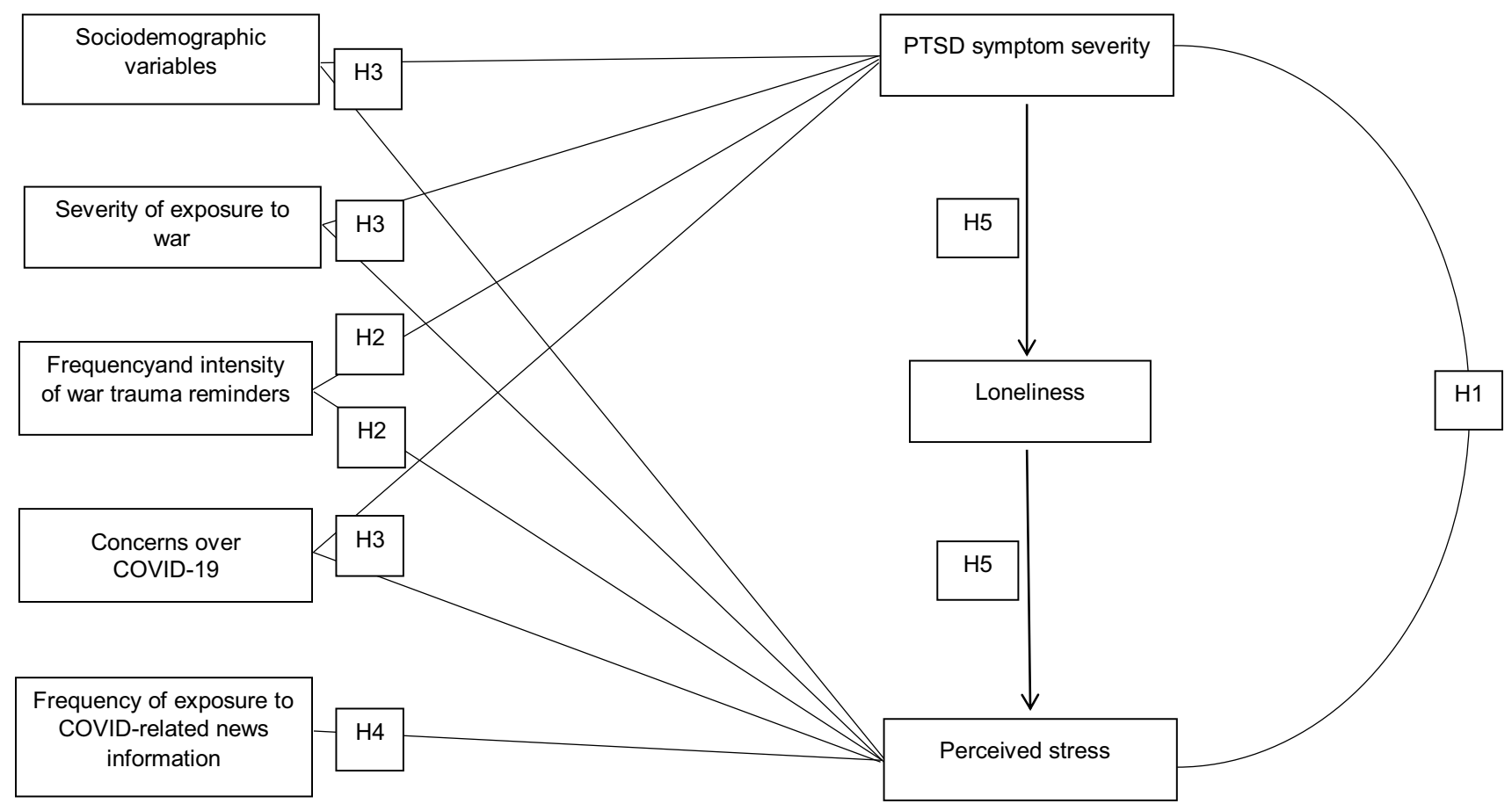

Fig. 1 Graphical Representation of Study Hypotheses

H1: Severity of PTSD symptoms would be positively correlated with perceived stress.

H2: Both frequency and intensity of exposure to war trauma reminders would be associated with higher levels of perceived stress and PTSD symptom severity.

H3: Sociodemographic variables, variables related to severity of exposure to war, and higher concerns over COVID-19 would be associated with PTSD symptom severity and perceived stress levels.

H4: More frequent exposure to COVID-related news information would be associated with higher perceived stress levels.

H5: Loneliness during the pandemic would mediate the relationship between PTSD symptom severity and perceived stress level.

\section{Method}

\section{Participants and Procedure}

Participants in the current study included 123 people from Bosnia and Herzegovina. As stated in the pre-registration, this study only included citizens born in or before 1992 to capture relevant war trauma experience.

Data for this study were collected as a part of the COVIDiSTRESS Global Survey. General information on the survey can be found in the Yamada et al. (2021). To test the hypotheses of the current study, the questions assessing the severity of exposure to war, the UCLA-TRI, and the PCPTSD were introduced as temporary conditional elements of the survey for participants from Bosnia and Herzegovina. All instruments that went through translation-back translation procedures were also validated through both panel and back-translation processes. Data collection took place between May 16th and June 14th, 2020.

Recruitment calls for participation in an online Qualtrics ${ }^{\mathrm{TM}}$ study was made primarily through social networks, and one of the researchers appeared in several local media. The purpose of the media appearance was to inform the general audience about the COVIDiSTRESS Global Survey and to emphasize its importance. Specific aims of the current study were not revealed in order to avoid misleading or raising expectations in participants about how to respond to the survey. Contacts were established through the Association of Psychologists, mental health centers, non-governmental organizations and civil services to advertise the study to the public. Participants were not paid for agreeing to participate. This study has been approved by the Ethics Committee of the Association of Psychologists of the Federation of Bosnia and Herzegovina. The procedures used in the current study adhered to the tenets of the Declaration of Helsinki. Informed consent was obtained from all participants. Given that two scales measure war trauma reminders and PTSD symptoms, participants were advised to consult the nearest mental health center or private psychotherapist in case they 
experienced uneasiness. Also, they could choose to end their participation at any point after they have started the survey.

\section{Measures and Instruments}

Sociodemographic Variables Data were collected on age, gender, marital status, level of education, and number of people a person lives with during COVID-19 isolation.

COVID-19 Related Variables Participants were also asked if they or any member of their close environment (immediate family or close friends) were in a high-risk group (e.g., pregnant, elderly or had a pre-existing medical condition) for disease. The total number of people staying in the same place was assessed with two items asking how many (1) other adults or (2) children are staying together in the same place with the participant during the COVID-19 relative isolation.

Participants were also asked about their concerns about coronavirus using five questions developed for the COVIDiSTRESS Global Survey. Participants were asked "How much do you agree that you are concerned about the consequences of the coronavirus (1) for yourself, (2) for your family, (3) for your close friends, (4) for your country, and (5) for other countries across the globe?". Items were rated on a 6-point Likert type scale $(0=$ Strongly disagree, $5=$ Strongly agree). In the current study, Cronbach's alpha coefficient was .90 .

In addition, participants were asked about information sources and their media behavior during the period where COVID-19 has impacted Bosnia and Herzegovina. This scale was developed for the COVIDiSTRESS Global Survey. The items were (1) "I have sought information from the Bosnia and Herzegovina's government more frequently than usual"; (2) "I have sought information from independent news outlets in Bosnia and Herzegovina more frequently than usual"; (3) "I have sought information from news outlets outside of Bosnia and Herzegovina more frequently than usual"; (4) "I have sought information from friends and family more frequently than usual"; and (5) "I have sought information via social media more frequently than usual". Items were rated on a 6 -point Likert type scale $(0=$ Strongly disagree, $5=$ Strongly agree $)$. In the current study, Cronbach's alpha coefficient was .83 .

Loneliness Subjective feelings of loneliness during the COVID-19 pandemic were assessed using the Three Item Loneliness Scale (Hughes et al., 2004). This measure was designed by selecting items from the 20 -item revised UCLA Loneliness Scale (Russell et al., 1980). The items asked how often participants have felt that they (1) lacked companionship, (2) were left out, and/or (3) isolated in the last week, rated on a 5-point scale ranging from 1 (Never) to 5 (Very often). Mean scores were computed to obtain a perceived loneliness score with higher scores indicating higher levels of loneliness. The scale showed good reliability, and convergent and discriminant validity (Hughes et al., 2004). For the current study, the items were translated to Bosnian and then back-translated to English by two independent experts. Cronbach's alpha coefficient was .75 in this study.

Variables Related to the Severity of Exposure to War Participants were asked about the severity of exposure to war including time spent in Bosnia and Herzegovina between years 1992 and 1995 (having left the country at the beginning of the war, being forcibly displaced, and having spent the total period of war in Bosnia and Herzegovina); firsthand experience of war as a civilian or a soldier; loss of close ones during the war; and possible war-related injury coded as 1 (No) or 2 (Yes).

War Trauma Reminders Frequency and intensity of war trauma reminders were assessed using four items from the UCLA Trauma Reminder Inventory (UCLA-TRI; Steinberg et al., 2001). For assessing frequency of reminders, two items were (1) "How many times during the past month did restrictions on places that you can go during the COVID19 pandemic remind you of the 1992-1995 war in Bosnia and Herzegovina?" and (2) "How many times during the past month did news of social and economic instability and tensions during the COVID-19 pandemic remind you of the 1992-1995 war in Bosnia and Herzegovina?". Two items were rated on a 5 -point Likert type scale $(0=$ None, $4=M o s t)$. For assessing intensity of reminders, two items were used: (1) "How upset (bothered, sad, scared) did you get when restrictions on places that you can go during the COVID-19 pandemic reminded you of the 1992-1995 war in Bosnia and Herzegovina?" and (2) "How upset (bothered, sad, scared) did you get when news of political instability and tensions during the COVID-19 pandemic reminded you of the 1992-1995 war in Bosnia and Herzegovina?". The rationale for including these questions was supported by the results of the previous study by Turjačanin et al. (2020). In this study, the authors showed that the pandemic situation in Bosnia and Herzegovina was accompanied by an almost complete halt of economic processes, and challenges in the field of politics, health, and social environment. The items were rated on a 5 -point Likert type scale $(0=$ Not at all, $4=A$ whole lot). Item scores were summed to obtain total scores for frequency and intensity of reminders. The items were translated to Bosnian and then back-translated to English by two independent experts. Cronbach's alpha coefficient was .85 for the scale assessing frequency, and .80 for the scale assessing intensity of reminders in this study.

PTSD Symptom Severity Severity of PTSD symptoms was assessed using The Primary Care PTSD Screen for DSM-5 
(PC-PTSD; Prins et al., 2015). The PC-PTSD includes five yes/no questions $(0=N o, 1=Y e s)$ about how previous exposure to the 1992-1995 war in Bosnia and Herzegovina has affected participants over the past month. Mean scores were used to obtain a symptom severity score, with higher scores indicating higher severity of PTSD symptoms. Previous research has shown good test-retest reliability and predictive validity (Prins et al., 2003) for the PC-PTSD, and also excellent diagnostic utility (Prins et al., 2016). In the current study, Cronbach's alpha coefficient was .73 for the PCPTSD. For the purpose of this study, the items were translated to Bosnian and then back-translated to English by two independent experts.

Perceived Stress The 10-item Perceived Stress Scale (PSS; Cohen et al., 1983; Cohen \& Williamson, 1988) was administered to measure the level of perceived stress in participants. The items are rated on a 5-point scale from 0 (Never) to 4 (Very often). Item scores (including four reverse scored) were summed to obtain a total stress score, with higher scores indicating higher stress levels. In the current study, the adapted version of this scale was used (Hudek-Knežević et al., 1999). Cronbach's alpha coefficient was .83 in our sample.

\section{Data Analysis}

We included all respondents that provided complete answers to all questions on the UCLA-TRI, the Three-Item Loneliness Scale, the PC-PTSD, and the PSS. We excluded all partial or incomplete responses (a total of 29 responses). Since our sample was relatively small, missing values on exposure to COVID-related information were replaced with the median value for that variable (Harrell, 2015).

Power analyses for the current study was conducted using the G*Power 3.1 software (Faul et al., 2009), showing that for correlation analysis, a minimum sample size of 84 was required to achieve medium effect size, $80 \%$ power and alpha error probability of 5\%. All other analyses were performed using IBM SPSS (Version 25). Correlation and multiple regression analyses were employed to examine the associations between study variables. Time spent during the war was dummy-coded prior to the analysis. Since $92.7 \%$ of participants were employed at the time of data collection, we did not include employment status in the analysis. The Kolmogorov-Smirnov test for normality revealed that measures of severity of PTSD symptoms, loneliness, and both frequency and intensity of trauma reminders violated the normality assumption. Due to the violation of normality assumptions, intercorrelations between study variables were calculated using the Spearman rank correlation coefficient $\left(r_{s}\right)$. Based on the recommendations by McMillan and Foley (2011) for indicating effect sizes for correlations, coefficients of determination $\left(r_{s}^{2}\right)$ were computed. $r_{s}^{2}$ explains the proportion (or percentage) of variation in the dependent variable explained by the independent variable. Accordingly, $r^{2}=.01$ can be considered a small effect size, .09 represents a medium and .25 a large effect size (Téllez et al., 2015). The mediation hypotheses of loneliness were tested through the PROCESS macro (Hayes, 2018) using Model 4 with bias-corrected bootstrapping derived from 5000 resampling. We concluded that there was a significant indirect effect (at alpha $=.05)$ if the $95 \%$ confidence interval did not include zero. The magnitude of the indirect effect in the mediation model was estimated using the kappa-squared $\left(\kappa^{2}\right)$ based on the recommendations by Preacher and Kelley (2011). Similar to effect sizes for correlation coefficients, Preacher and Kelley (2011, pp. 107-108) suggest interpreting $\mathrm{K}^{2}$ values of $.01, .09$, and .25 to reflect small, medium, and large effect sizes, respectively.

\section{Results}

\section{Characteristics of the Study Sample}

Table 1 presents sociodemographic characteristics of the study participants.

The number of adults staying with participants during the COVID-19 relative isolation ranged between 0 and $4(M=1.32, S D=1.23)$, and the number of children ranged between 0 and $3(M=0.69, S D=0.88)$ with total of number of people ranging between 0 and $5(M=2.03$, $S D=1.62)$. Fifty-eight $(47.2 \%)$ participants reported that they or any of family members or close friends were in a high-risk group for COVID-19 while 57 (46.3\%) participants responded as "No" in this assessment and eight (6.5\%) participants were not sure.

In terms of first-hand war experience, 100 participants $(81.3 \%)$ reported experiencing the war as a civilian, 7 (5.7\%) as a soldier, and $16(13.0 \%)$ did not experience the war directly. From our participants, 114 (92.7\%) did not suffer any injury from the war whereas $5(4.1 \%)$ did experience an injury that was not permanent, and 4 (3.3\%) suffered a permanent injury as a result of the war. In addition, $61(49.6 \%)$ have suffered loss during the war whereas the remaining $62(50.4 \%)$ did not suffer any losses. Out of all participants, $16(13 \%)$ have left the country at the beginning of the war, $78(63.4 \%)$ spent the total period of the war in Bosnia and Herzegovina, and 24 (19.5\%) were displaced. 
Table 1 Sociodemographic Representation of the Sample $(N=123)$

\begin{tabular}{|c|c|c|c|c|c|}
\hline Variable & $f$ & $\%$ & Mean & $S D$ & Range \\
\hline Age & & & 41.34 & 9.46 & $28-85$ \\
\hline \multicolumn{6}{|l|}{ Gender } \\
\hline Women & 92 & 74.8 & & & \\
\hline Men & 31 & 25.2 & & & \\
\hline \multicolumn{6}{|l|}{ Marital status } \\
\hline Single & 23 & 18.7 & & & \\
\hline Married/cohabiting & 80 & 65 & & & \\
\hline Divorced/widowed & 14 & 11.4 & & & \\
\hline Prefer not to say & 5 & 4.1 & & & \\
\hline Did not respond & 1 & 0.8 & & & \\
\hline \multicolumn{6}{|l|}{ Education level } \\
\hline Up to nine years of school & 2 & 1.6 & & & \\
\hline Up to twelve years of school & 11 & 8.9 & & & \\
\hline $\begin{array}{l}\text { Some college education or } \\
\text { equivalent }\end{array}$ & 10 & 8.1 & & & \\
\hline College/bachelor/MA degree & 79 & 64.2 & & & \\
\hline PhD degree & 21 & 17.1 & & & \\
\hline \multicolumn{6}{|l|}{ Employment status } \\
\hline Full-time employed & 107 & 87 & & & \\
\hline Part-time employed & 5 & 4.1 & & & \\
\hline Retired & 4 & 3.3 & & & \\
\hline Unemployed & 3 & 2.4 & & & \\
\hline Self-employed & 2 & 1.6 & & & \\
\hline Student & 1 & 0.8 & & & \\
\hline Not applicable & 1 & 0.8 & & & \\
\hline
\end{tabular}

Table 2 Means, Standard Deviations (SD), and Ranges of Continuous Study Variables

\begin{tabular}{llll}
\hline Variable & Mean & SD & Range \\
\hline Exposure to COVID-related information & 3.63 & 1.07 & $1-6$ \\
COVID-19 related concerns & 3.69 & 1.09 & $1-6$ \\
Loneliness during the pandemic & 2.47 & 0.91 & $1-5$ \\
Frequency of wartrauma reminders & 1.89 & 1.12 & $0-4$ \\
Intensity of wartrauma reminders & 1.65 & 1.07 & $0-4$ \\
Severity of PTSD symptoms & 1.11 & 1.40 & $0-5$ \\
Perceived stress & 15.91 & 5.88 & $2-30$ \\
\hline
\end{tabular}

\section{Testing the Associations between Variables of Interest, PTSD Symptom Severity, and Stress}

Table 2 depicts means, standard deviations (SD), and ranges of continuous variables. The examination of zero-order correlation coefficients revealed that severity of PTSD symptoms was positively related to perceived stress, $r_{s}=.37$, $p<.001, r_{s}^{2}=.14$, thus confirming Hypothesis 1 . Further examination of coefficients also indicated that both frequency and intensity of exposure to war trauma reminders were associated with higher levels of perceived stress (frequency: $r_{s}=.30, p=.001, r_{s}{ }_{s}=.09$; intensity: $r_{s}=.38$, $p<.001, r_{s}{ }_{s}=.14$ ) and PTSD symptom severity (frequency: $r_{s}=.50, p<.001, r_{s}^{2}=.25$; intensity: $r_{s}=.57, p<.001$, $r_{s}^{2}=.32$ ). When the associations between sociodemographic variables, PTSD symptom severity, and perceived stress levels were examined, it was found that gender, age, level of education, high-risk status for COVID-19, and number of people a person lives with during COVID-19 isolation were not associated with perceived stress or severity of PTSD symptoms at $p<.05$. Being married or cohabiting was related to lower levels of perceived stress during the COVID-19 pandemic, $r_{s}=-.27, p=.003, r_{s}^{2}=.07$. Among variables related to severity of exposure to war, being forcibly displaced during the 1992-1995 war, $r_{s}=.19, p=.038$, $r_{s}^{2}=.04$, and not having left the country at the beginning of war, $r_{s}=-.20, p=.039, r_{s}^{2}=.04$, were associated with higher perceived stress. Forced displacement during the war was also related to higher severity of PTSD symptoms, $r_{s}=.24, p=.008, r_{s}^{2}=.06$. Increase in concerns over COVID-19 was found to be positively and significantly correlated with perceived stress, $r_{s}=.29, p=.001, r^{2}{ }_{s}=.08$, and severity of PTSD symptoms, $r_{s}=.24, p=.007, r_{s}^{2}=.06$. Finally, the association between exposure to COVID-related news information and perceived stress levels was examined. However, this association was not significant at $p<.05$.

In order to explore the variables predicting severity of PTSD symptoms and perceived stress and to examine the contributions of each independent variable, multiple regression analyses with forward stepwise variable selection were performed. Accordingly, variables showing statistically significant associations $(\mathrm{p}<.05)$ with psychological outcomes in the bivariate analysis were selected for inclusion in the regression models. Since multiple tests were run when examining the associations between variables of interest, severity of PTSD symptoms, and perceived stress, Bonferroni correction was applied to account for the risk of Type I error and the statistical significance of the models were determined as $\mathrm{p}<.025$ for outcomes. Results showed that loneliness, intensity of war trauma reminders, and being forcibly displaced during the war accounted for $38 \%$ variance in severity of PTSD symptoms. Similarly, $38 \%$ variance in perceived stress was accounted for by loneliness during the pandemic and COVID-19 related concerns. Summary statistics are shown in Table 3.

\section{Testing the Mediating Role of Loneliness}

The indirect effect of severity of PTSD symptoms on perceived stress levels through loneliness was examined for testing Hypothesis 5. The mediation model explained 34\% of the variance in perceived stress $(F(2,120)=31.90, p<.001)$. Severity of PTSD symptoms was positively associated with 
Table 3 Results of Stepwise Multiple Regression Analyses PredictingSeverity of PTSD Symptoms and Perceived Stress

\begin{tabular}{|c|c|c|c|c|c|c|c|c|c|c|}
\hline \multirow[t]{3}{*}{ Independent variables } & \multicolumn{10}{|c|}{ Dependent variables } \\
\hline & \multicolumn{5}{|c|}{ Severity of PTSD symptoms } & \multicolumn{5}{|c|}{ Perceived stress } \\
\hline & Adjusted $R^{2}$ & $\beta$ & SE & $t$ & $p$ & Adjusted $R^{2}$ & $\beta$ & SE & $t$ & $p$ \\
\hline Loneliness & .09 & .32 & .13 & 3.65 & $<.001$ & .34 & .58 & .49 & 7.72 & $<.001$ \\
\hline Intensityof wartrauma reminders & .35 & .54 & .10 & 7.02 & $<.001$ & .35 & .17 & .43 & 2.17 & .032 \\
\hline Frequencyof wartrauma reminders & .35 & .13 & .16 & 1.03 & .304 & .35 & .02 & .67 & 0.16 & .872 \\
\hline COVID-19 related concerns & .35 & .10 & .10 & 1.23 & .222 & .38 & .20 & .42 & 2.61 & .010 \\
\hline Maritalstatus $^{\mathrm{a}}$ & - & - & - & - & - & .40 & -.17 & .93 & -2.24 & .027 \\
\hline $\begin{array}{l}\text { Having left the country at the begin- } \\
\text { ning of the war }\end{array}$ & - & - & - & - & - & .41 & -.12 & 1.40 & -1.71 & .091 \\
\hline Being forcibly displaced ${ }^{\mathrm{b}}$ & .38 & .18 & .26 & 2.50 & .014 & .42 & .08 & 1.42 & -1.54 & .126 \\
\hline
\end{tabular}

${ }^{\mathrm{a}} 1=$ single/divorced, 2 = married/cohabiting; ${ }^{\mathrm{b}} 1=$ no, $2=$ yes

Fig. 2 Unstandardized Regression Weights Showing that Severity of PTSD Symptoms Exerting a Significant Indirect Effect on Perceived Stress Through Loneliness

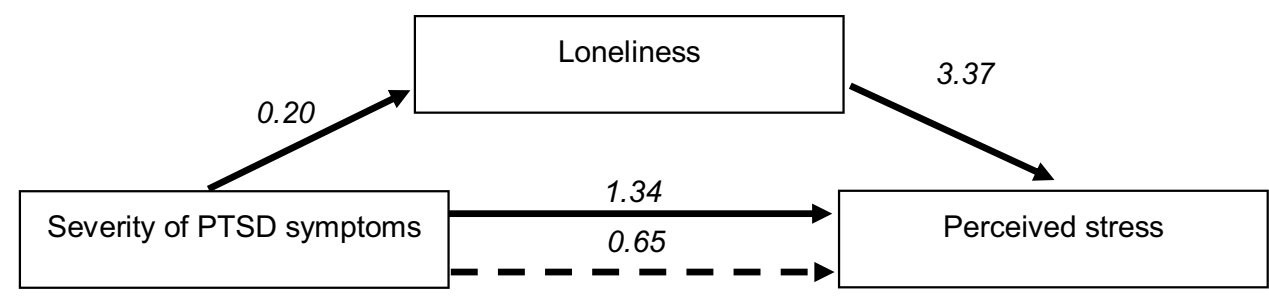

loneliness $(\beta=.32, p<.001)$, which in turn was related to perceived stress $(\beta=.52, p<.001)$. The residual direct effect was still statistically significant $(\beta=.16, p=.048)$, meaning that loneliness during the COVID-19 pandemic partially mediated the relation between severity of PTSD symptoms and perceived stress (indirect effect $=.16,95 \% \mathrm{CI}=.08$ to .26). The $\mathrm{K}^{2}$ value of $.17 \mathrm{implied}$ a medium effect size for the indirect effect (Preacher \& Kelly, 2011). Thus, Hypothesis 5 was supported (see Fig. 2).

\section{Discussion}

This pre-registered study examined people's reactions to preventive measures related to the COVID-19 pandemic in a sample who had been previously exposed to war in Bosnia and Herzegovina. To our best knowledge, this study was the first to focus on loneliness, PTSD symptoms, and stress along with war trauma related experiences simultaneously in the context of the COVID-19 pandemic, and sheds some light on what happens to those that already are stressed and/ or have PTSD symptoms during times of public health crisis and how reminders of past trauma can relate to current stress levels and severity of PTSD symptoms among traumaexposed populations. Having in mind specific samples (survivors of 1992-1995 war in Bosnia and Herzegovina), and the extraordinary situation of lockdown, curfew, and other prevention measures, this research brings unique insights into the influence trauma reminders and loneliness may have on PTSD symptom severity and perceived stress.

In this study, we tested five hypotheses deriving from previous literature. As predicted by our first hypothesis, severity of PTSD symptoms correlated positively with perceived stress. Previous studies have found that posttraumatic stress and perceived stress co-exist (Besser et al., 2009; Frasier et al., 2004; Hu et al., 2014). Our finding confirms this association in the context of the COVID-19 pandemic in a previously traumatized population. It has long been acknowledged that stress can impact individual functioning negatively; when individuals perceive the situation as stressful, and their resources are inadequate to handle the environmental stimuli (Lazarus \& Folkman, 1984). The COVID-19 pandemic can be perceived as stressful and traumatic because of the negative cognitive appraisal of the event (Ehlers \& Clark, 2000; Lazarus \& Folkman, 1984). Furthermore, in a longitudinal study by Dekel et al. (2013), PTSD symptoms predicted negative cognitions of the self and the world in a sample exposed to war trauma. Therefore, existing PTSD symptoms can be further intensified by negative appraisals during a pandemic, thereby increasing stress.

Partially confirming our second hypothesis, in a previously traumatized population, we found the intensity of exposure to war trauma reminders to be positively associated with higher levels of PTSD symptom severity. That is in line with the Howell et al. (2015) study in which the authors indicated that the exposure to trauma reminders could predict posttraumatic stress symptoms. It is well known that 
the repeated exposure to trauma-related content is likely to reinforce rumination and intrusive thoughts, activate fear circuitry, and perhaps contribute to development of flashbacks (Bourne et al., 2013). Yet, it is also possible that preexisting PTSD symptomatology might be associated with experiencing reminders as more intense in crisis situations such as the current pandemic. During ongoing threats, the media plays an important role in delivering information from trusted sources, communicating risk, and abating rumours and public anxiety. However, the media can make individuals repeatedly exposed to trauma-related content, and affect psychological responses to traumatic events. As time progresses and the threat continues, repeated exposure can create a cycle of distress as people with greatest concerns seek out media coverage and become more distressed due to heightened exposure (Garfin et al., 2020). Nevertheless, contrary to our expectations, we found that the amount of consumption of COVID-related news coverage was not significantly associated with neither severity of PTSD symptoms nor stress. In our study, we assessed this variable using items about seeking information from the government, news outlets, social media, and friends and family more frequently than usual. Although frequent exposure to social media/ news concerning COVID-19 is a risk factor for psychological distress (Xiong et al., 2020), media platforms relate to well-being both in maladaptive and adaptive patterns (Eden et al., 2020), and can actually strengthen social support and direct individuals to resources for needs (Galea et al., 2020). This suggests that in addition to the amount of the exposure, the content can also affect psychological responses as Garfin et al. (2020) have discussed earlier. Using the media and approaching others for information about COVID-19 might have provided support and information about necessary resources to the participants in our study, buffering the adverse impact of frequent exposure. Also, it is possible that due to the low trust in media, participants found the provided information neither very important nor reliable. Having in mind that the level of trust was not measured, we cannot conclude its influence with certainty.

Considering our third hypothesis, we found none of sociodemographic variables (gender, age, level of education, marital status, number of people a person lives with during COVID-19 isolation and being at high risk for disease) to not be associated with PTSD symptom severity or perceived stress in our sample. When variables related to severity of exposure to war were examined, results showed that forced displacement during the war was related to higher severity of PTSD symptoms. These results are consistent with the findings of Howell et al. (2015), implying that the post-war exposure to trauma reminders in adolescents and youth who survived the 1992-1995 war in Bosnia and Herzegovina and suffered from casualties predicted PTSD symptoms. Moreover, these show that future research should focus on specific war related experiences, and adversities during the war can help us understand how reminders are experienced during the pandemic as well as how they are related to PTSD symptom severity levels. In addition, we also found a positive association between increase in concerns over COVID-19 with perceived stress. This shows that concerns over disease during the pandemic act as significant stressors. Taken together, these findings deepen our understanding on the relevance of both risk and protective factors for mental health in war-experienced populations.

Finally, in accordance with our fifth hypothesis, we found loneliness to mediate the relationship between PTSD symptom severity and perceived stress, suggesting that the adverse impact of existing PTSD symptomatology on perceived stress is mediated by adverse experiences during the pandemic (i.e., lack of companionship, feeling left out, being isolated). These findings are in line with previous research on the mitigatory effects of social support and close attachments to others on perceived stress in people who have experienced active combat (Hobfoll et al., 1991; Mitchell et al., 2011). During the COVID-19 pandemic, social support has also been suggested to buffer the negative effects of perceived severity of the disease on loneliness (Wang et al., 2021). However, Miller et al. (2002) suggested that in people who have experienced trauma, social isolation might help to avoid distressing social interactions which would remind them of previous trauma. Previously Nowland et al. (2018) have shown that lonely people are typically more sensitive to threats and perceive more stress than their non-lonely counterparts. Thus, there should be persistent efforts to reduce feelings of loneliness in individuals previously exposed to traumatic events.

Nevertheless, this study has certain methodological limitations that require consideration. Given that this study was conducted while Bosnia and Herzegovina was suffering a rise in coronavirus infections, we had to rely on an online survey only. Hence, we might have lost those participants who, due to the higher levels of stress and/or PTSD could not complete the online survey. A face-to-face approach would have helped us control for equal gender distribution; however, $74.8 \%$ of total respondents were females, which represents a limitation future studies should overcome. Moreover, we relied on self-report measures in this crosssectional study which prevents us inferring causal relationships between variables. Also, we did not know the severity of PTSD or stress before the pandemic and cannot exclude if these levels were lower before this study. Moreover, daily stressors such as social isolation can tax people's coping resources and slow down healing from persistent effects of trauma in war-affected communities (Miller \& Rasmussen, 2010). It would be important for future studies to control for any specific stressful and material conditions occurring during the pandemic or different reminders which might have 
contributed to outcomes examined in the study. In addition, the strategies of coping with stress have not been examined, hence it would be difficult to conclude if the increase in the severity of PTSD symptoms in the presence of trauma reminders might have been dependent on a certain coping style as it was previously examined by Pineles et al. (2011) in assault survivors.

Our sample was specific as it included people who experienced the 1992-1995 war in Bosnia and Herzegovina. Hence, potential replication studies should take into consideration to include only those who were born while the war (or similar catastrophe) was in place and who did not migrate out during the war. Moreover, what is distinctive about a traumatic experience and COVID-19 for a survivor of war can be ensued through the active conceptualising and meaning making of that experience, a process which the survivor undertakes. Therefore, one of the suggestions for future research will be a qualitative study that can ensure additional sets of data that can complement our quantitative study and provide deeper insights into the nature of war trauma reminders. Finally, this study mostly focused on risk factors for adverse mental health outcomes. Future studies may also consider protective factors which may buffer the impact of risk factors on PTSD symptoms and stress.

This study is novel as it explored those that have been previously traumatised and therefore may be more vulnerable to the psychosocial effects of the global COVID-19 pandemic. The long-lasting effects of war and the reminders of trauma appear to be associated with PTSD symptoms and perceived stress in the global COVID-19 pandemic and warrants further attention. Stress and PTSD symptoms are compounded with loneliness during the pandemic, which mediates both effects. Moreover, specific war experiences and intensity of reminders of such experiences seem to be related to negative psychological outcomes during the pandemic. Taken together, our findings highlight that populations who have been subjected to war experiences might be at risk in managing severe crisis situations more than 25 years later. As such, this study provides valuable information for mental health professionals, epidemiologists, researchers, and policy makers on how to establish preventive measures and support networks for vulnerable populations.

Public health crises warrants authorities to adopt an integrative response with psychosocial interventions into public health emergency preparedness and response (Peng et al., 2020; Raphael \& Wooding, 2006). To prevent additive negative consequences, specialised mental health intervention programmes would benefit from meeting the needs of populations who have been previously traumatised as they will require individual assessment and more targeted interventions to meet their complex needs while also accounting for the impact of loneliness during the pandemic. As the COVID-19 pandemic transitions to a somewhat normality, it will be important to foster social networks and active contact, and to form structures in institutions to enhance safety and security as well as facilitate resilience among those who are vulnerable.

Data Availability Statement The datasets generated during and/or analysed during the current study are available in the Open Science Framework repository, https://osf.io/r4vt9/files/

Author Contributions All authors contributed to the study conception and design. Data collection was performed by Alma Jeftić. Data analysis was conducted by Gözde Ikizer. The manuscript was written by all authors. All authors read and approved the final manuscript.

\section{Declarations}

Ethical Approval This study has been approved by the Ethics Committee of the Association of Psychologists in Federation Bosnia and Herzegovina. The procedures used in this study adhere to the tenets of the Declaration of Helsinki.

Informed Consent Informed consent was obtained from all participants included in the study. Given that two scales measure war trauma reminders and PTSD symptoms, participants were advised to consult the nearest mental health center or private psychotherapist in case they experienced uneasiness. Also, they could choose to end their participation at any point after they have started the survey.

Conflict of Interest The authors declare that they have no conflict of interest.

\section{References}

Ai, A. L., Peterson, C., \& Ubelhor, D. (2002). War-related trauma and symptoms of posttraumatic stress disorder among adult Kosovar refugees. Journal of Traumatic Stress, 15(2), 157-160. https://doi. org/10.1023/A:1014864225889

Beller, J., \& Wagner, A. (2018). Loneliness, social isolation, their synergistic interaction, and mortality. Health Psychology, 37(9), 808-813. https://doi.org/10.1037/hea0000605

Besser, A., Neria, Y., \& Haynes, M. (2009). Adult attachment, perceived stress, and PTSD among civilians exposed to ongoing terrorist attacks in southern Israel. Personality and Individual Differences, 47(8), 851-857. https://doi.org/10.1016/j.paid.2009.07.003

Bourne, C., Mackay, C. E., \& Holmes, E. A. (2013). The neural basis of flashback formation: The impact of viewing trauma. Psychological Medicine, 43, 1521-1533. https://doi.org/10.1017/S0033 291712002358

Brewin, C. R., Dalgleish, T., \& Joseph, S. (1996). A dual representation theory of posttraumatic stress disorder. Psychological Review, 103(4), 670-686. https://doi.org/10.1037/0033-295x.103.4.670

Brooks, S. K., Webster, R. K., Smith, L. E., Woodland, L., Wessely, S., Greenberg, N., \& Rubin, G. J. (2020). The psychological impact of quarantine and how to reduce it: Rapid review of the evidence. The Lancet, 395(10227), 912-920. https://doi.org/10.1016/S01406736(20)30460-8

Castelli, L., Di Tella, M., Benfante, A., \& Romeo, A. (2020). The spread of COVID-19 in the Italian population: Anxiety, depression, and post-traumatic stress symptoms. The Canadian Journal of Psychiatry, 65(10), 731-732. https://doi.org/10.1177/07067 43720938598 
Carballo, M., Smajkic, A., Zeric, D., Dzidowska, M., Gebre-Medhin, J., \& Van Halem, J. (2004). Mental health and coping in a war situation: The case of Bosnia and Herzegovina. Journal of Biosocial Science, 36, 463-477. https://doi.org/10.1017/S002193200 4006753

Chen, B., Li, Q.-x., Zhang, H., Zhu, J.-y., Yang, X., Wu, Y.-h., Xiong, J., Li, F., Wang, H., \& Chen, Z.-t. (2020). The psychological impact of COVID-19 outbreak on medical staff and the general public. Current Psychology Advance online publication. https:// doi.org/10.1007/s12144-020-01109-0

Cheng, C., Barceló, J., Hartnett, A. S., Kubinec, R., \& Messerschmidt, L. (2020). COVID-19 government response event dataset (CoronaNet v.1.0). Nature Human Behavior, 4, 756-768. https://doi.org/ 10.1038/s41562-020-0909-7

Cohen, S., Kamarck, T., \& Mermelstein, R. (1983). A global measure of perceived stress. Journal of Health and Social Behavior, 24(4), 385-396. https://doi.org/10.2307/2136404

Cohen, S., \& Williamson, G. (1988). Perceived stress in a probability sample of the United States. In S. Spacapan \& S. Oskamp (Eds.), Social psychology of health (pp. 31-67). Sage.

Comtesse, H., Powell, S., Soldo, A., Hagl, M., \& Rosner, R. (2019). Long-term psychological distress of Bosnian war survivors: An 11-year follow-up of former displaced persons, returnees, and stayers. BMC Psychiatry, 19(1), 1. https://doi.org/10.1186/ s12888-018-1996-0

Daly, M., \& Robinson, E. (2021). Psychological distress and adaptation to the COVID-19 crisis in the United States. Journal of Psychiatric Research, 136, 603-609. https://doi.org/10.1016/j.jpsychires. 2020.10.035

de Jong-Gierveld, J. (1998). A review of loneliness: Concept and definitions, determinants and consequences. Reviews in Clinical Gerontology, 8, 73-80. https://doi.org/10.1017/S0959259898008090

Dekel, S., Peleg, T., \& Solomon, Z. (2013). The relationship of PTSD to negative cognitions: A 17-year longitudinal study. Psychiatry, 76(3), 241-255. https://doi.org/10.1521/psyc.2013.76.3.241

Di Crosta, A., Palumbo, R., Marchetti, D., Ceccato, I., La Malva, P., Maiella, R., Cipi, M., Roma, P., Mammarella, N., Verrocchio, M. C., \& Di Domenico, A. (2020). Individual differences, economic stability, and fear of contagion as risk factors for PTSD symptoms in the COVID-19 emergency. Frontiers in Psychology, 11, 2329. https://doi.org/10.3389/fpsyg.2020.567367

Avaz, D. (2020). Od danas nema policijskog sata u RS. https://avaz.ba/ vijesti/bih/571626/od-danas-nema-policijskog-sata-u-rs.

Durakovic-Belko, E., Kulenovic, A., \& Dapic, R. (2003). Determinants of posttraumatic adjustment in adolescents from Sarajevo who experienced war. Journal of Clinical Psychology, 59(1), 27-40. https://doi.org/10.1002/jclp.10115

Eden, A. L., Johnson, B. K., Reinecke, L., \& Grady, S. M. (2020). Media for coping during COVID-19 social distancing: Stress, anxiety, and psychological well-being. Frontiers in Psychology, 11, 577639. https://doi.org/10.3389/fpsyg.2020.577639

Ehlers, A., \& Clark, D. M. (2000). A cognitive model of posttraumatic stress disorder. Behaviour Research and Therapy, 38, 319-345. https://doi.org/10.1016/s0005-7967(99)00123-0

Faul, F., Erdfelder, E., Buchner, A., \& Lang, A.-G. (2009). Statistical power analyses using $G^{*}$ power 3.1: Tests for correlation and regression analyses. Behavior Research Methods, 41, 1149-1160. https://doi.org/10.3758/BRM.41.4.1149

Frasier, P. Y., Belton, L., Hooten, E., Campbell, M. K., DeVellis, B., Benedict, S., Carillo, C., Gonzalez, P., Kelsey, K., \& Meier, A. (2004). Disaster down east: Using participatory action research to explore intimate partner violence in eastern North Carolina. Health Education \& Behavior, 31(4_suppl), 69S-84S. https://doi. org/10.1177/1090198104266035

Galea, S., Merchant, R. M., \& Lurie, N. (2020). The mental health consequences of COVID19 and physical distancing: The need for prevention and early intervention. JAMA Internal Medicine, 180(6), 817-818. https://doi.org/10.1001/jamainternmed.2020. 1562

Garfin, D. R., Silver, R. C., \& Holman, E. A. (2020). The novel coronavirus (COVID-2019) outbreak: Amplification of public health consequences by media exposure. Health Psychology, 39(5), 355-357. https://doi.org/10.1037/hea0000875

Glad, K. A., Hafstad, G. S., Jensen, T. K., \& Dyb, G. (2017). A longitudinal study of psychological distress and exposure to trauma reminders after terrorism. Psychological Trauma: Theory, Research, Practice, and Policy, 9(Suppl 1), 145-152. https://doi. org/10.1037/tra0000224

Gobbi, S., Płomecka, M. B., Ashraf, Z., Radziński, P., Neckels, R., Lazzeri, S., Dedić, A., Bakalović, A., Hrustić, L., Skórko, B., Eshaghi, S., Almazidou, K., Rodríguez-Pino, L., Alp, A. B., Jabeen, H., Waller, V., Shibli, D., Behnam, M. A., Arshad, A. H., et al. (2020). Worsening of preexisting psychiatric conditions during the COVID-19 pandemic. Frontiers in Psychiatry, 11, 581426. https://doi.org/10.3389/fpsyt.2020.581426

Harrell, F. E. (2015). Regression modeling strategies. Springer.

Hayes, A. F. (2018). Introduction to mediation, moderation, and conditional process analysis: A regression-based approach (2nd ed.). Guilford Press.

Hilton, C. (1997). Media triggers of post-traumatic stress disorder 50 years after the second world war. International Journal of Geriatric Psychiatry, 12(8), 862-867. https://doi.org/10.1002/(SICI) 1099-1166(199708)12:8

Hobfoll, S. E., Spielberger, C. D., Breznitz, S., Figley, C., Folkman, S., Lepper-Green, B., Meichenbaum, D., Milgram, N. A., Sandler, I., Sarason, I., \& van der Kolk, B. (1991). War-related stress: Addressing the stress of war and other traumatic events. American Psychologist, 46(8), 848-855. https://doi.org/10.1037/0003-066X. 46.8.848

Holmes, E. A., O'Connor, R. C., Perry, H. V., Tracey, I., Wessely, S., Arseneault, L., Ballard, C., Christensen, H., Silver, R. C., Everall, I., Ford, T., John, A., Kabir, T., King, K., Madan, I., Michie, S., Przybylski, A. K., Shafran, R., Sweeney, A., et al. (2020). Multidisciplinary research priorities for the COVID-19 pandemic: A call for action for mental health science. The Lancet Psychiatry, 7(6), 547-560. https://doi.org/10.1016/S2215-0366(20)30168-1

Howell, K. H., Kaplow, J. B., Layne, C. M., Benson, M. A., Compas, B. E., Katalinski, R., Pasalic, H., Bosankic, N., \& Pynoos, R. (2015). Predicting adolescent posttraumatic stress in the aftermath of war: Differential effects of coping strategies across trauma reminder, loss reminder, and family conflict domains. Anxiety, Stress \& Coping, 28(1), 88-104. https://doi.org/10.1080/10615 806.2014.910596

Hughes, M. E., Waite, L. J., Hawkley, L. C., \& Cacioppo, J. T. (2004), A short scale for measuring loneliness in large surveys: Results from two population-based studies. Research on Aging, 26(6), 655-672. https://doi.org/10.1177/0164027504268574

Hu, E., Koucky, E. M., Brown, W. J., Bruce, S. E., \& Sheline, Y. I. (2014). The role of rumination in elevating perceived stress in posttraumatic stress disorder. Journal of Interpersonal Violence, 29(10), 1953-1962. https://doi.org/10.1177/0886260513511697

Hudek-Knežević, J., Kardum, I., \& Lesić, R. (1999). Efekti percipiranog stresa i stilova suočavanja na tjelesne simptome. Društvena Istraživanja, 8, 543-561 https://hrcak.srce.hr/20324

Ikizer, G., Karanci, A. N., Gul, E., \& Dilekler, I. (2021). Posttraumatic stress, growth, and depreciation during the COVID-19 pandemic: Evidence from Turkey. European Journal of Psychotraumatology, 12(1), 1872966. https://doi.org/10.1080/20008198.2021.1872966

Jankovic, A., \& Cehajic-Clancy, S. (2020, June 10). Social and behavioural responses during the COVID-19 pandemic in Bosnia and Herzegovina. Open Science framework. https://doi.org/10.31234/ osf.io/s83ru 
Jeftić, A. (2019). Social aspects of memory. Stories of victims and perpetrators from Bosnia and Herzegovina. Routledge.

Jeftić, A., Ikizer, G., Tuominen, J., Chrona, S., Kumaga, R., \& Yamada, Y. (2020). Stay at home: Connection between the coronavirus pandemic, prevention measures and war trauma in Bosnia and Herzegovina. Open Science Framework. https://doi.org/10.17605/ OSF.IO/R4VT9

Karatzias, T., Shevlin, M., Murphy, J., McBride, O., Ben-Ezra, M., Bentall, R. P., Vallières, F., \& Hyland, P. (2020). Posttraumatic stress symptoms and associated comorbidity during the COVID19 pandemic in Ireland: A population-based study. Journal of Traumatic Stress, 33(4), 365-370. https://doi.org/10.1002/jts. 22565

Kevers, R., Rober, P., Derluyn, I., \& Haene, L. D. (2016). Remembering collective violence: Broadening the notion of traumatic memory in post-conflict rehabilitation. Culture, Medicine, and Psychiatry, 40, 620-640. https://doi.org/10.1007/s11013-016-9490-y

Klarić, M., Klarić, B., Stevanović, A., Grković, J., \& Jonovska, S. (2007). Psychological consequences of war trauma and postwar social stressors in women in Bosnia and Herzegovina. Croatian Medical Journal, 48(2), 167-176.

Kuwert, P., Knaevelsrud, C., \& Pietrzak, R. H. (2014). Loneliness among older veterans in the United States: Results from the National Health and resilience in veterans study. The American Journal of Geriatric Psychiatry, 22(6), 564-569. https://doi.org/ 10.1016/j.jagp.2013.02.013

Layne, C. M., Warren, J. S., Saltzman, W. R., Fulton, J. B., Steinberg, A. M., \& Pynoos, R. S. (2006). Contextual influences on posttraumatic adjustment: Retraumatization and the roles of revictimization, posttraumatic adversities, and distressing reminders. In L. A. Schein, H. I. Spitz, G. M. Burlingame, \& P. R. Muskin (Eds.), \& S. Vargo (collaborator), psychological effects of catastrophic disasters: Group approaches to treatment (pp. 235-286). Haworth Press.

Lazarus, R. S., \& Folkman, S. (1984). Stress, appraisal and coping. Springer.

Liu, C. H., Zhang, E., Wong, G. T. F., \& Hyun, S. (2020). Factors associated with depression, anxiety, and PTSD symptomatology during the COVID-19 pandemic: Clinical implications for US young adult mental health. Psychiatry Research, 290, 113172. https://doi.org/10.1016/j.psychres.2020.113172

Lo Coco, G., Gentile, A., Bosnar, K., Milovanović, I., Bianco, A., Drid, P., \& Pišot, S. (2021). A cross-country examination on the fear of COVID-19 and the sense of loneliness during the first wave of COVID-19 outbreak. International Journal of Environmental Research and Public Health, 18, 2586. https://doi.org/10.3390/ ijerph18052586

Luo, M., Guo, L., Yu, M., Jiang, W., \& Wang, H. (2020). The psychological and mental impact of coronavirus disease 2019 (COVID19) on medical staff and general public - A systematic review and meta-analysis. Psychiatry Research, 291, 113190. https://doi.org/ 10.1016/j.psychres.2020.113190

McMillan, J. H., \& Foley, S. (2011). Reporting and discussing effect size: Still the road less traveled? Practical assessment. Research \& Evaluation, 16(16). https://doi.org/10.7275/b6pz-ws55

Miller, K. E., \& Rasmussen, A. (2010). War exposure, daily stressors, and mental health in conflict and post-conflict settings: Bridging the divide between trauma-focused and psychosocial frameworks. Social Science \& Medicine, 70(1), 7-16. https://doi.org/10.1016/j. socscimed.2009.09.029

Miller, K. E., Omidian, P., Rasmussen, A., Yaqubi, A., \& Daudzai, H. (2008). Daily stressors, war experiences, and mental health in Afghanistan. Transcultural Psychiatry, 45(4), 611-638.

Miller, K. E., Weine, S. M., Ramic, A., Brkic, N., Bjedic, Z. D., Smajkic, A., Boskailo, E., \& Worthington, G. (2002). The relative contribution of war experiences and exile-related stressors to levels of psychological distress among Bosnian refugees. Journal of Traumatic Stress, 15(5), 377-387. https://doi.org/ 10.1023/A: 1020181124118

Mitchell, M. M., Gallaway, M. S., Millikan, A., \& Bell, M. R. (2011). Combat stressors predicting perceived stress among previously deployed soldiers. Military Psychology, 23(6), 573-586. https:// doi.org/10.1080/08995605.2011.616478

Mooren, G. T. M., \& Kleber, R. J. (2001). The impact of war in Bosnia and Herzegovina: Devastated trust. International Journal of Mental Health, 30(2), 6-21. https://doi.org/10.1080/00207 411.2001.11449515

Nowland, R., Robinson, S. J., Bradley, B. F., Summers, V., \& Qualter, P. (2018). Loneliness, HPA stress reactivity and social threat sensitivity: Analyzing naturalistic social challenges. Scandinavian Journal of Psychology, 59(5), 540-546. https:// doi.org/10.1111/sjop.12461

Okorn, I., Jahović, S., Dobranić-Posavec, M., Mladenović, J., \& Glasnović, A. (2020). Isolation in the COVID-19 pandemic as re-traumatization of war experiences. Croatian Medical Journal, 61(4), 371-376. https://doi.org/10.3325/cmj.2020.61.371

Papageorgiou, V., Frangou-Garunovic, A., Iordanidou, R., Yule, W., Smith, P., \& Vostanis, P. (2000). War trauma and psychopathology in Bosnian refugee children. European Child \& Adolescent Psychiatry, 9, 84-90. https://doi.org/10.1007/s007870050002

Park, C. L., Russell, B. S., Fendrich, M., Finkelstein-Fox, L., Hutchison, M., \& Becker, J. (2020). Americans' COVID-19 stress, coping, and adherence to CDC guidelines. Journal of General Internal Medicine, 35(8), 2296-2303. https://doi.org/10.1007/ s11606-020-05898-9

Peng, D., Wang, Z., \& Xu, Y. (2020). Challenges and opportunities in mental health services during the COVID-19 pandemic. General Psychiatry, 33(5), e100275. https://doi.org/10.1136/ gpsych-2020-100275

Pfefferbaum, B., \& North, C. S. (2020). Mental health and the Covid19 pandemic. The New England Journal of Medicine, 383, 510 512. https://doi.org/10.1056/NEJMp2008017

Pineles, S. L., Mostoufi, S. M., Ready, C. B., Street, A. E., Griffin, M. G., \& Resick, P. A. (2011). Trauma reactivity, avoidant coping, and PTSD symptoms: A moderating relationship? Journal of Abnormal Psychology, 120(1), 240-246. https://doi.org/10. 1037/a0022123

Powell, S., Butollo, W., \& Hagl, M. (2010). Missing or killed: The differential effect on mental health in women in Bosnia and Herzegovina of the confirmed or unconfirmed loss of their husbands. European Psychologist, 15(3), 185-192. https://doi.org/ 10.1027/1016-9040/a000018

Preacher, K. J., \& Kelley, K. (2011). Effect size measures for mediation models: Quantitative strategies for communicating indirect effects. Psychological Methods, 16(2), 93-115. https://doi.org/ $10.1037 / \mathrm{a} 0022658$

Prins, A., Bovin, M. J., Kimerling, R., Kaloupek, D. G., Marx, B. P., Pless Kaiser, A., \& Schnurr, P. P. (2015). The primary care PTSD screen for DSM-5 (PC-PTSD-5). [measurement instrument]. https://www.ptsd.va.gov/professional/assessment/scree ns/pc-ptsd.asp

Prins, A., Bovin, M. J., Smolenski, D. J., Mark, B. P., Kimerling, R., Jenkins-Guarnieri, M. A., Kaloupek, D. G., Schnurr, P. P., Pless Kaiser, A., Leyva, Y. E., \& Tiet, Q. Q. (2016). The primary care PTSD screen for DSM-5 (PC-PTSD-5): Development and evaluation within a veteran primary care sample. Journal of General Internal Medicine, 31, 1206-1211. https://doi.org/10. 1007/s11606-016-3703-5

Prins, A., Ouimette, P., Kimerling, R., Cameron, R. P., Hugelshofer, D. S., Shaw-Hegwer, J., Thrailkill, A., Gusman, F. D., \& Sheikh, J. I. (2003). The primary care PTSD screen (PC-PTSD): 
Development and operating characteristics. Primary Care Psychiatry, 9(1), 9-14. https://doi.org/10.1185/135525703125002 360

Radio Slobodna Evropa (2020). Prvi slučaj virusa korona u Bosni $i$ Hercegovini, zaraženi otac i dijete. https://www.slobodnaevropa. org/a/30469735.html

Radiosarajevo.ba (2020). U cijeloj Bosni i Hercegovini uveden policijski sat. https://radiosarajevo.ba/vijesti/bosna-i-hercegovina/radio sarajevoba-saznaje-u-cijeloj-bih-uveden-policijski-sat/371093

Raphael, B., \& Wooding, S. (2006). Longer-term mental health interventions for adults following disasters and mass violence. In E. C. Ritchie, P. J. Watson, \& M. J. Friedman (Eds.), Interventions following mass violence and disasters: Strategies for mental health practice (pp. 174-192). Guilford Press.

Repišti, S., Jovanović, N., Kuzman, M. R., Medved, S., Jerotić, S., Ribić, E., Majstorović, T., Simoska, S. M., Novotni, L., Milutinović, M., Stoilkovska, B. B., Radojičić, T., Ristić, I., Zebić, M., Pemovska, T., \& Russo, M. (2020). How to measure the impact of the COVID-19 pandemic on quality of life: COV19-QoL - The development, reliability and validity of a new scale. Global Psychiatry, 3(2), 201-210. https://doi.org/10.2478/ gp-2020-0016

Ringdal, G. I., Ringdal, K., \& Simkus, A. (2008). War experiences and war-related distress in Bosnia and Herzegovina eight years after war. Croatian Medical Journal, 49, 75-86. https://doi.org/ 10.3325/cmj.2008.1.75

Russell, D., Peplau, L. A., \& Cutrona, C. E. (1980). The revised UCLA loneliness scale: Concurrent and discriminant validity evidence. Journal of Personality and Social Psychology, 39(3), 472-480. https://doi.org/10.1037/0022-3514.39.3.472

Serafini, G., Parmigiani, B., Amerio, A., Aguglia, A., Sher, L., \& Amore, M. (2020). The psychological impact of COVID-19 on the mental health in the general population. QJM: An International Journal of Medicine, 113(8), 531-537. https://doi.org/10. 1093/qjmed/hcaa201

Shemyakina, O. N., \& Plagnol, A. C. (2013). Subjective well-being and armed conflict: Evidence from Bosnia-Herzegovina. Social Indicators Research, 113(3), 1129-1152. https://doi.org/10.1007/ s11205-012-0131-8

Silver, R. C., Holman, E. A., Andersen, J. P., Poulin, M., McIntosh, D. N., \& Gil-Rivas, V. (2013). Mental- and physical-health effects of acute exposure to media images of the September 11, 2001, attacks and the Iraq war. Psychological Science, 24, 1623-1634. https://doi.org/10.1177/0956797612460406

Šljivo, A., Kačamaković, M., \& Quraishi, I. (2020). Fear and depression among residents of Bosnia and Herzegovina during COVID19 outbreak - internet survey. Psychiatria Danubina, 32(2), 266272. https://doi.org/10.24869/psyd.2020.266

Smith, P., Perrin, S., Yule, W., \& Rabe-Hesketh, S. (2001). War exposure and maternal reactions in the psychological adjustment of children from Bosnia-Hercegovina. Journal of Child Psychology and Psychiatry, 42(3), 395-404. https://doi.org/10.1111/14697610.00732

Solomon, Z., Bensimon, M., Greene, T., Horesh, D., \& Ein-Dor, T. (2015). Loneliness trajectories: The role of posttraumatic symptoms and social support. Journal of Loss and Trauma, 20(1), 1-21. https://doi.org/10.1080/15325024.2013.815055

Southwick, S. M., Sippel, L., Krystal, J., Charney, D., Mayes, L., \& Pietrzak, R. (2016). Why are some individuals more resilient than others: The role of social support. World Psychiatry, 15(1), 77-79. https://doi.org/10.1002/wps.20282

Streb, M., Conway, M. A., \& Michael, T. (2017). Conditioned responses to trauma reminders: How durable are they over time and does memory integration reduce them? Journal of Behavior Therapy and Experimental Psychiatry, 57, 88-95. https://doi.org/ 10.1016/j.jbtep.2017.04.005
Tang, W., Hu, T., Hu, B., Jin, C., Wang, G., Xie, C., Chen, S., \& Xu, J. (2020). Prevalence and correlates of PTSD and depressive symptoms one month after the outbreak of the COVID-19 epidemic in a sample of home-quarantined Chinese university students. Journal of Affective Disorders, 274, 1-7. https://doi.org/10.1016/j.jad. 2020.05.009

Téllez, A., García, C. H., \& Corral-Verdugo, V. (2015). Effect size, confidence intervals and statistical power in psychological research. Psychology in Russia: State of the Art, 8(3), 27-47. https://doi. org/10.11621/pir.2015.0303

Tsur, N., Defrin, R., Lahav, Y., \& Solomon, Z. (2018). The traumatized body: Long-term PTSD and its implications for the orientation towards bodily signals. Psychiatry Research, 261, 281-289. https://doi.org/10.1016/j.psychres.2017.12.083

Turjačanin, V., Puhalo, S., Damnjanović, K., \& Pralica, M. (2020). The new normal: Perception, attitudes and behavior of the citizens of Bosnia and Herzegovina at the beginning of the COVID-19 pandemic. Friedrich Ebert Stiftung.

Van der Kolk, B. (2000). Posttraumatic stress disorder and the nature of trauma. Dialogues in Clinical Neuroscience, 2(1), 7-22.

Van der Kolk, B. A., \& Fisler, R. (1995). Dissociation and the fragmentary nature of traumatic memories: Overview and exploratory study. Journal of Traumatic Stress, 8(4), 505-525. https://doi.org/ 10.1002/jts.2490080402

Van der Velden, P. G., Pijnappel, B., \& van der Meulen, E. (2018). Potentially traumatic events have negative and positive effects on loneliness, depending on PTSD-symptom levels: Evidence from a population-based prospective comparative study. Social Psychiatry and Psychiatric Epidemiology, 53, 195-206. https://doi.org/ 10.1007/s00127-017-1476-8

Wang, Y., Ariyo, T., Liu, H., \& Ma, C. (2021). Does psychosocial support buffer the effect of COVID-19 related stressors on mental health among Chinese during quarantine? Current Psychology. Advance online publication. https://doi.org/10.1007/ s12144-021-01663-1

Wang, C., Riyu, P., Wan, X., Tan, Y., Xu, L., McIntyre, R. S., Choo, F. N., Tran, B., Ho, R., Sharma, V. K., \& Ho, C. (2020). A longitudinal study on the mental health of general population during the COVID-19 epidemic in China. Brain, Behavior, and Immunity, 87, 40-48. https://doi.org/10.1016/j.bbi.2020.04.028

Xiong, J., Lipsitz, O., Nasri, F., Lui, L. M. W., Gill, H., Phan, L., Chen-Li, D., Iacobucci, M., Ho, R., Majeed, A., \& McIntyre, R. S. (2020). Impact of COVID-19 pandemic on mental health in the general population: A systematic review. Journal of Affective Disorders, 277, 55-64. https://doi.org/10.1016/j.jad.2020.08.001

Yamada, Y., Ćepulić, D.-B., Coll-Martín, T., Debove, S., Gautreau, G., Han, H., Rasmussen, J., Tran, T. P., Travaglino, G. A., COVIDiSTRESS Global Survey Consortium, and Lieberoth, A. (2021). COVIDiSTRESS Global Survey dataset on psychological and behavioural consequences of the COVID-19 outbreak. Scientific Data, 8, 3. https://doi.org/10.1038/s41597-020-00784-9

Zoellner, L. A., Ojalehtob, H. J., Rosencrans, P., Walker, R. W., Garcia, N. M., Sheikha, I. S., \& Bedard-Gilligan, M. A. (2020). Anxiety and fear in PTSD. In M. T. Tull \& N. A. Kimbrel (Eds.), Emotion in posttraumatic stress disorder: Etiology, assessment, neurobiology, and treatment (pp. 43-63). Academic Press. https://doi.org/ 10.1016/B978-0-12-816022-0.00002-8

Publisher's Note Springer Nature remains neutral with regard to jurisdictional claims in published maps and institutional affiliations. 